C. Ton-That et al.

\title{
Surface Electronic Properties of ZnO Nanoparticles
}

\author{
Cuong Ton-That*, Matthew R. Phillips, Matthew Foley and Steve J. Moody \\ Department of Physics and Advanced Materials, University of Technology Sydney, P.O. Box \\ 123, NSW 2007, Australia
}

Anton P. J. Stampfl

Bragg Institute, Bld-87, Australian Nuclear Science and Technology Organisation

PMB 1, Menai, NSW 2234, Australia

* Corresponding author. fax: +61.2.95142219, tel: +61.2.95142201.
Email address: cuong.ton-that@uts.edu.au

\begin{abstract}
The surface electronic structure of $\mathrm{ZnO}$ nanoparticles has been studied with photoemission and x-ray absorption spectroscopies. Contrary to expectation, ZnO:Zn phosphor nanoparticles were found to contain a lower oxygen vacancy density on the surface than undoped $\mathrm{ZnO}$ counterparts, but oxygen vacancies are in different chemical environments. Cathodoluminescence shows strong green luminescence from the $\mathrm{ZnO}: \mathrm{Zn}$ surface, while the undoped nanoparticles exhibit only the near-band-edge emission. The results indicate the involvement of surface oxygen vacancies in the previously unexplained green luminescence from the $\mathrm{ZnO}: \mathrm{Zn}$ material.
\end{abstract}


C. Ton-That et al.

Text

Characterisation of electronic structure is important for understanding the properties and reactivity of solid surfaces. For nanoparticles the contribution of surface to their electronic and optical properties is expected to be significant because of their large surface to volume ratio. $\mathrm{ZnO}$ nanoparticles are currently of technological importance and considerable scientific interest. A substantial number of published papers have dealt with the fabrication of $\mathrm{ZnO}$ nanostructures and their applications such as catalysis, UV-light emitters and transparent high-power electronics [1]. Recent theoretical calculations and existing models of methanol synthesis using $\mathrm{ZnO}$ nanocatalysts suggest that oxygen vacancies on the $\mathrm{ZnO}$ surface could act as active sites for $\mathrm{CO}$ and $\mathrm{CO}_{2}$ chemisorption during methanol synthesis [2, 3]. In addition, surface defects and impurities have been reported to quench the excitonic luminescence of $\mathrm{ZnO}[4,5]$ since they can act as trapping centres to compete with the near-band-edge (NBE) emission. These studies indicate that key properties of $\mathrm{ZnO}$ nanostructures may depend critically on their surfaces.

Strunskus et al. [6] have studied the valence band structure of $\mathrm{ZnO}$ powders using $\mathrm{x}$-ray emission spectroscopy. This technique, however, is not a surface-sensitive probe because of the large mean free path of x-ray photons in matter and consequently all recorded spectral data are dominated by bulk contributions. A key question to address is to what extent the surface electronic structure of $\mathrm{ZnO}$ nanoparticles affect their luminescent properties. In this letter, we report on the electronic structure of undoped $\mathrm{ZnO}$ and $\mathrm{ZnO}: \mathrm{Zn}$ phosphor nanoparticles studied with surface science techniques. 


\section{Ton-That et al.}

The undoped $\mathrm{ZnO}$ nanoparticles with an average diameter of $25 \mathrm{~nm}$ were chosen for this study to provide a large surface area-to-volume ratio without introducing quantum size effects since the particle size is much larger than the Bohr radius of $2.34 \mathrm{~nm}$ [7]. The specimen was obtained from Advanced Nanotechnology Ltd, Australia who fabricate the nanoparticles using a mechanochemical-processing ${ }^{\mathrm{TM}}$ technique. The $\mathrm{ZnO} \mathrm{Zn}$ phosphor nanoparticles with an average diameter of $500 \mathrm{~nm}$ (Phosphor Technology Ltd., England) was obtained by annealing $\mathrm{ZnO}$ in a $\mathrm{Zn}$ atmosphere. Photoemission spectroscopy and x-ray absorption nearedge structure (XANES) were conducted on the low-energy spherical grating monochromator (LSGM) and wide-range SGM (24A) beamlines at the National Synchrotron Radiation Research Centre (Taiwan, ROC). The XANES spectra were recorded in the surface-sensitive partial electron yield (PEY) mode with a retardation voltage of $-100 \mathrm{~V}$. Because the probing depths of XPS and XANES (PEY mode) are similar (typical probing depth is $<5 \mathrm{~nm}$ ), it is attractive to use these techniques as complementary tools to investigate the electronic structure and chemical states of $\mathrm{O}$ and $\mathrm{Zn}$ atoms on the surface. For each sample, several scans were registered on the same spot in order to monitor x-ray beam damage; however, no significant changes within the measurement time (approximately 10-15 minutes) were detected. To investigate the depth-dependent luminescence properties of the nanoparticles, cathodoluminescence (CL) spectra were collected using a FEI Quanta 200 SEM equipped with a Gatan MonoCL3 system.

CL spectra of the nanoparticles, corrected for system response, obtained at $300 \mathrm{~K}$ are shown in Figure 1. The spectrum was acquired from the $\mathrm{ZnO} \mathrm{Zn}$ surface by using a minimum accelerating voltage of $200 \mathrm{~V}$, which corresponds to an excitation depth of $<1 \mathrm{~nm}$. The spectrum exhibits a broad green emission peak which can be fitted by two Gaussian components centred at $2.50 \mathrm{eV}$ and $2.26 \mathrm{eV}$, which have been recently attributed to radiative 


\section{Ton-That et al.}

recombination involving surface oxygen vacancies [8]. In contrast, an accelerating voltage of $4 \mathrm{kV}$ was required to produce sufficient signal from the undoped $\mathrm{ZnO}$ nano-particles, suggesting the presence of a greater number of non-radiative centres or a surface dead layer. In addition, its CL emission spectrum is dominated by a near-band-edge (NBE) emission at $3.3 \mathrm{eV}$, the green emission is negligible.

XPS survey spectra of the nanoparticles revealed only zinc and oxygen signals and no other impurities were detected. The $\mathrm{O} / \mathrm{Zn}$ atomic ratios of the undoped and $\mathrm{ZnO}: \mathrm{Zn}$ nanoparticles, computed using the peak areas of $\mathrm{O} 1 s$ and $\mathrm{Zn} 2 p_{3 / 2}$, are 0.67 and 0.92 ( \pm 0.10 uncertainty), respectively. The $\mathrm{O} / \mathrm{Zn}$ ratio for the undoped nanoparticles is significantly smaller than unity, suggesting that their surface is non-stoichiometric with a large oxygen deficiency. At first sight, these results appear surprising given the expectation that the $\mathrm{ZnO}: \mathrm{Zn}$ nanoparticles would be more oxygen deficient. However, it is entirely consistent with a detailed analysis of the $\mathrm{O} 1 s$ spectrum. It is well known that the $\mathrm{Zn} 2 p$ doublet is not highly sensitive to its atomic state [9], while the shift of O $1 s$ level due to the chemical environment of the atom could be several eV. Figure 2 compares the $\mathrm{O} 1 \mathrm{~s}$ spectra of the undoped $\mathrm{ZnO}$ and $\mathrm{ZnO}: \mathrm{Zn}$ nanoparticles. The binding energy scale was referenced to the $\mathrm{Au} 4 f_{7 / 2}$ at $84.0 \mathrm{eV}$. It is clear that the $\mathrm{O} 1 \mathrm{~s}$ line shapes of the two specimens differ substantially on the high-binding-energy side of the peak. The $\mathrm{O} 1 \mathrm{~s}$ line shape of the undoped $\mathrm{ZnO}$ is similar to those of hydroxylated ZnO surfaces [10] and can be resolved by a Lorentzian fitting distribution into two peaks at 530.6 and $532.9 \mathrm{eV}$ (inset of Figure 2). The dominant peak at $530.6 \mathrm{eV}$ is associated with the $\mathrm{O}^{2-}$ ion in $\mathrm{ZnO}$, while the $532.9 \mathrm{eV}$ has been attributed to zinc oxyhydroxide $[\mathrm{ZnO}(\mathrm{OH})]$ and suboxides of $\mathrm{ZnO}[10,11]$. The XPS results show that the undoped $\mathrm{ZnO}$ surface is in a large oxygen-deficient state and confirm the existence of a surface dead layer of luminescence as observed by CL. 


\section{Ton-That et al.}

Figure 3 presents the valence band spectra of the undoped and $\mathrm{ZnO}: \mathrm{Zn}$ nanoparticles together with that of a clean $\mathrm{ZnO}(0001)$ single crystal [12] (MTI Corp., USA) for comparison. The valence band of the single crystal spectrum exhibits three main features centred at 10.5, 7.6 (labelled B) and $4.5 \mathrm{eV}$ (labelled A), which have been assigned to $\mathrm{Zn} 3 d$, mixed $\mathrm{Zn} 4 s-\mathrm{O} 2 p$ and $\mathrm{O} 2 p$ states, respectively $[13,14]$. All the spectra inhibit the same spectral onset at $2.4 \mathrm{eV}$ below the Fermi level, $E_{\mathrm{F}}$ (estimated by a linear extrapolation of the leading edge of the valence band [15]). There are significant differences in the overall spectral shape of the nanoparticles. Peaks A and B both shift to higher binding energies while the energy difference between the features is smaller than that of the crystal. It is worth noting that the $\mathrm{ZnO}$ nanoparticles are not subject to the same treatment in ultrahigh vacuum as the $\mathrm{ZnO}$ single crystal, thus the atomic structure of their surfaces is expected to be considerably different from that of the crystal. In comparison with the crystal, the most pronounced difference is the reduction in the $\mathrm{Zn} 3 d$ intensity for the nanoparticles and the enhancement of the valence band region at $5-7 \mathrm{eV}$ for the $\mathrm{ZnO}: \mathrm{Zn}$ nanoparticles, which is likely due to an increased $\mathrm{Zn}$ $4 s-\mathrm{O} 2 p$ hybridisation. This again indicates that surface oxygen atoms in $\mathrm{ZnO}: \mathrm{Zn}$ are in a different chemical environment from those on the undoped $\mathrm{ZnO}$ surface. It is striking that the Zn $3 d$ binding energy is barely affected probably because it is well-separated from other valence states and may be treated as a core-like chemically inert state [16].

Figure 4 shows the comparison of the O K-edge XANES spectra from the undoped $\mathrm{ZnO}$ and $\mathrm{ZnO}: \mathrm{Zn}$ nanoparticles. The spectral features predominantly reflect the $\mathrm{O} 2 p$ conduction band states. The region between 530 and $537 \mathrm{eV}$ (peaks A and B) can be attributed mainly to $\mathrm{O} 2 p$ hybridisation with highly dispersive Zn $4 s$ states, which form the bottom of the conduction band with peak $\mathrm{B}$ at $536.5 \mathrm{eV}$ due to the $\mathrm{O} 1 s \rightarrow 2 p$ excitation $[17,18]$. The region between 


\section{Ton-That et al.}

538 and $550 \mathrm{eV}$ (peaks C and D) can be assigned to O $2 p$ hybridised with $\mathrm{Zn} 4 p$ states. There is an observed difference in the absorption onset between the two specimens of $\sim 0.5 \mathrm{eV}$, likely due to the variation of the $\mathrm{O} 1 s$ binding energy. In addition, and more importantly, in comparison with the $\mathrm{ZnO}: \mathrm{Zn}$ specimen, the spectral features of the undoped nanoparticles are broader. This broadening, especially in relation to peak B, has been attributed to the presence of oxygen vacancies [19]. The inset of figure 4 shows the Zn $L_{3}$-edge XANES spectra, which mainly reflect the electron transitions $\mathrm{Zn} 2 p \rightarrow 3 d$ and $\mathrm{Zn} 2 p \rightarrow 4 s$ [17]. The spectral shape and features agree remarkably well with the spectra obtained from crystalline ZnO nanorods [17]. There are little differences between the undoped $\mathrm{ZnO}$ and $\mathrm{ZnO}: \mathrm{Zn}$ specimens, indicating similar chemical states of $\mathrm{Zn}$ atoms in the near-surface regions of the nanoparticles. Thus there are no significant Zn defect-related features such as Zn antisites or interstitials. From consideration of the photoemission spectroscopy and XANES results it is concluded that oxygen-deficient-related defects or oxygen vacancies, rather than $\mathrm{Zn}$ defects, are dominant factors controlling the luminescent properties of the $\mathrm{ZnO}$ nanoparticles. Although the stoichiometric deficiency of oxygen in the $\mathrm{ZnO}: \mathrm{Zn}$ material is less pronounced, it exhibits strong green luminescence, indicating the chemical environment of oxygen ions is the dominant factor for the emission.

The observation of a strong green emission from the $\mathrm{ZnO}: \mathrm{Zn}$ surface, together with the results from surface analysis, clearly indicates that the luminescence originates from the oxygen vacancies present at the particle surface. One obvious mechanism responsible for the complete quenching of the NBE emission in $\mathrm{ZnO}: \mathrm{Zn}$ is efficient energy transfer from excited electron-hole pairs to surface oxygen vacancies. It has been suggested that that the holes involved in the green luminescence are primarily trapped at the $\mathrm{ZnO}$ surface [20]. It is noted that the concept of surface recombination is not limited to $\mathrm{ZnO}$. The yellow luminescence of 
C. Ton-That et al.

$\mathrm{GaN}$ is known to possess similar characteristics to the green emission in $\mathrm{ZnO}$ and has also been suggested to originate from the surface [21]. The surface may therefore have a crucial role in optoelectronic applications of wide band gap semiconductor nanostructures.

\section{Acknowledgements}

This work was supported by the Australian Synchrotron Research Program, which is funded by the Commonwealth of Australia under the Major National Research Facilities Program.

\section{References}

[1] For a review, see U. Ozgur, Y. I. Alivov, C. Liu, A. Teke, M. A. Reshchikov, S. Dogan, V. Avrutin, S. J. Cho, and H. Morkoc, J. Appl. Phys. 98 (2005) and references therein.

[2] S. A. French, A. A. Sokol, S. T. Bromley, C. R. A. Catlow, and P. Sherwood, Top. Catal. 24, 161 (2003).

[3] A. Janotti and C. G. Van de Walle, Phys. Rev. B 76, 165202 (2007).

[4] H. Zhou, H. Alves, D. M. Hofmann, W. Kriegseis, B. K. Meyer, G. Kaczmarczyk, and A. Hoffmann, Appl. Phys. Lett. 80, 210 (2002).

[5] G. Xiong, U. Pal, and J. G. Serrano, J. Appl. Phys. 101, 024317 (2007).

[6] T. Strunskus, O. Fuchs, L. Weinhardt, C. Heske, M. Guraya, M. Muhler, V. Staemmler, and C. Woll, J. Electron Spectrosc. Relat. Phenom. 134, 183 (2004).

[7] Y. Gu, I. L. Kuskovsky, M. Yin, S. O'Brien, and G. F. Neumark, Appl. Phys. Lett. 85, 3833 (2004).

[8] J. D. Prades, A. Cirera, J. R. Morante, and A. Comet, Thin Solid Films 515, 8670 (2007). 
C. Ton-That et al.

[9] A. Drici, G. Djeteli, G. Tchangbedji, H. Derouiche, K. Jondo, K. Napo, J. C. Bernede, S. Ouro-Djobo, and M. Gbagba, Phys. Status Solidi A-Appl. Res. 201, 1528 (2004).

[10] E. De la Rosa, S. Sepulveda-Guzman, B. Reeja-Jayan, A. Torres, P. Salas, N. Elizondo, and M. J. Yacaman, J. Phys. Chem. C 111, 8489 (2007).

[11] N. S. Ramgir, D. J. Late, A. B. Bhise, M. A. More, I. S. Mulla, D. S. Joag, and K. Vijayamohanan, J. Phys. Chem. B 110, 18236 (2006).

[12] The cleaning procedure consists of cycles of argon-ion sputtering ( $2 \mathrm{keV}, 15$ mins) and annealing in ultrahigh vacuum (1050 K, 60 mins) until no impurities could be

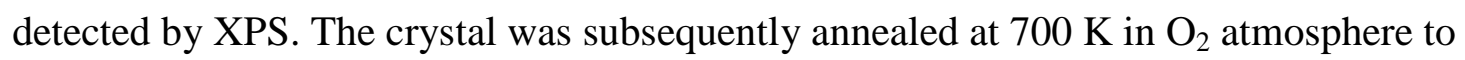
restore the surface stoichiometry.

[13] R. T. Girard, O. Tjernberg, G. Chiaia, S. Soderholm, U. O. Karlsson, C. Wigren, H. Nylen, and I. Lindau, Surf. Sci. 373, 409 (1997).

[14] J. W. Chiou, J. C. Jan, H. M. Tsai, C. W. Bao, W. F. Pong, M. H. Tsai, I. H. Hong, R. Klauser, J. F. Lee, J. J. Wu, and S. C. Liu, Appl. Phys. Lett. 84, 3462 (2004).

[15] Note that a tail exists on the valence band edge mainly due to the core-hole lifetime Lorentzian broadening of electronic states.

[16] C. McGuinness, C. B. Stagarescu, P. J. Ryan, J. E. Downes, D. F. Fu, K. E. Smith, and R. G. Egdell, Phys. Rev. B 68, 165104 (2003).

[17] J. W. Chiou, K. P. K. Kumar, J. C. Jan, H. M. Tsai, C. W. Bao, W. F. Pong, F. Z. Chien, M. H. Tsai, I. H. Hong, R. Klauser, J. F. Lee, J. J. Wu, and S. C. Liu, Appl. Phys. Lett. 85, 3220 (2004).

[18] C. L. Dong, C. Persson, L. Vayssieres, A. Augustsson, T. Schmitt, M. Mattesini, R. Ahuja, C. L. Chang, and J. H. Guo, Phys. Rev. B 70, 195325 (2004). 
C. Ton-That et al.

[19] S. Krishnamurthy, C. McGuinness, L. S. Dorneles, M. Venkatesan, J. M. D. Coey, J. G. Lunney, C. H. Pattersonb, K. E. Smith, T. Learmonth, P. A. Glans, T. Schmitt, and J. H. Guo, J. Appl. Phys. 99, 08M111 (2006).

[20] I. Shalish, H. Temkin, and V. Narayanamurti, Phys. Rev. B 69, 245401 (2004).

[21] I. Shalish, Y. Shapira, L. Burstein, and J. Salzman, J. Appl. Phys. 89, 390 (2001). 
C. Ton-That et al.

\section{Surface Electronic Properties of ZnO Nanoparticles}

\section{Figure Captions}

Fig. 1. CL spectra collected from the ZnO:Zn surface at an acceleration voltage of $200 \mathrm{~V}$ and from the undoped $\mathrm{ZnO}$ nanoparticles at $4 \mathrm{kV}$. The $\mathrm{ZnO}: \mathrm{Zn}$ spectrum exhibits a broad, strong green peak, which can be fitted with two Gaussians centred at 2.50 and $2.26 \mathrm{eV}$.

Fig 2. O 1 s core-level photoemission spectra obtained from the undoped $\mathrm{ZnO}$ and $\mathrm{ZnO}: \mathrm{Zn}$ nanoparticles. The spectra were normalised to the peak height. The spectrum for the undoped nanoparticles is broadened with a shoulder on the high-binding-energy side and can be resolved into two peaks which correspond to two chemically different environments (inset).

Fig. 3. Valence band spectra of the undoped $\mathrm{ZnO}$ and $\mathrm{ZnO}: \mathrm{Zn}$ nanoparticles together with that of a $\mathrm{ZnO}(0001)$ single crystal shown for comparison. The spectra were measured using a photon energy $h v=45 \mathrm{eV}$.

Fig. 4. O K-edge XANES spectra of the undoped (solid curve) and ZnO:Zn nanoparticles (dashed curve). The broadening of the spectral features, particularly in relation to peak B at $536 \mathrm{eV}$, is clear. Inset shows a comparison of $\mathrm{Zn} L_{3}$-edge XANES spectra of the nanoparticles. All the spectra were normalised so as to give the intensity of unity at $25-30$ eV above the absorption edge. 
C. Ton-That et al.

Figure 1

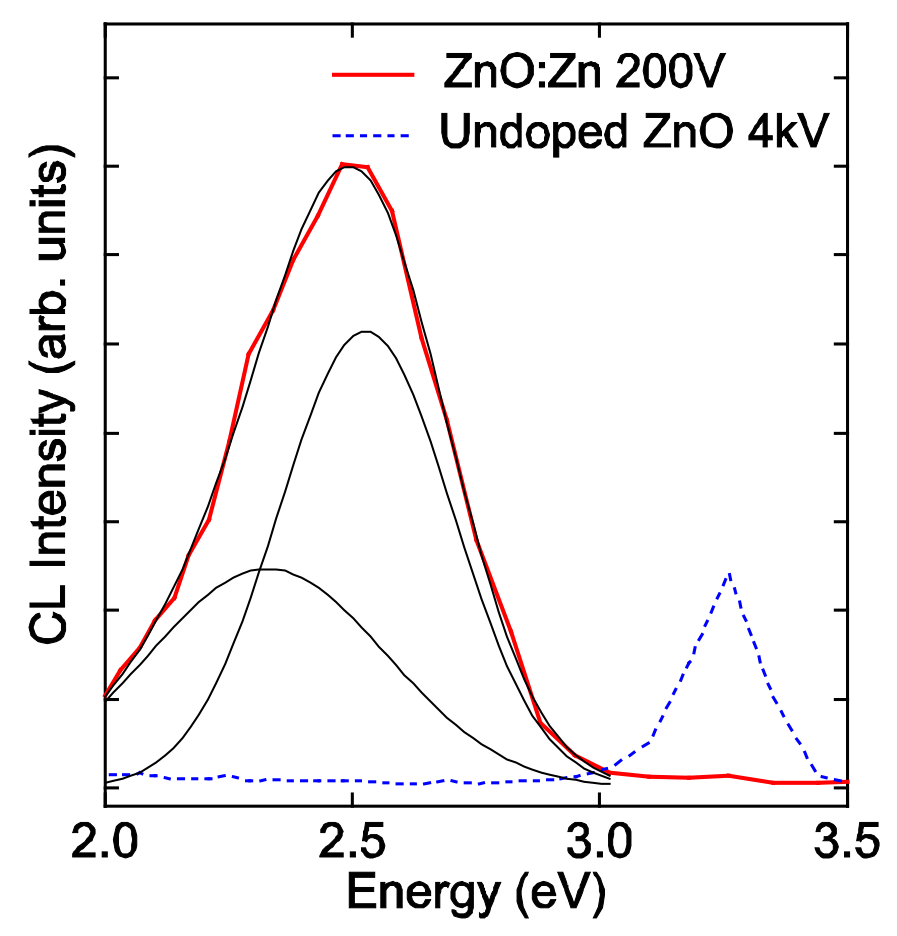


C. Ton-That et al.

Figure 2

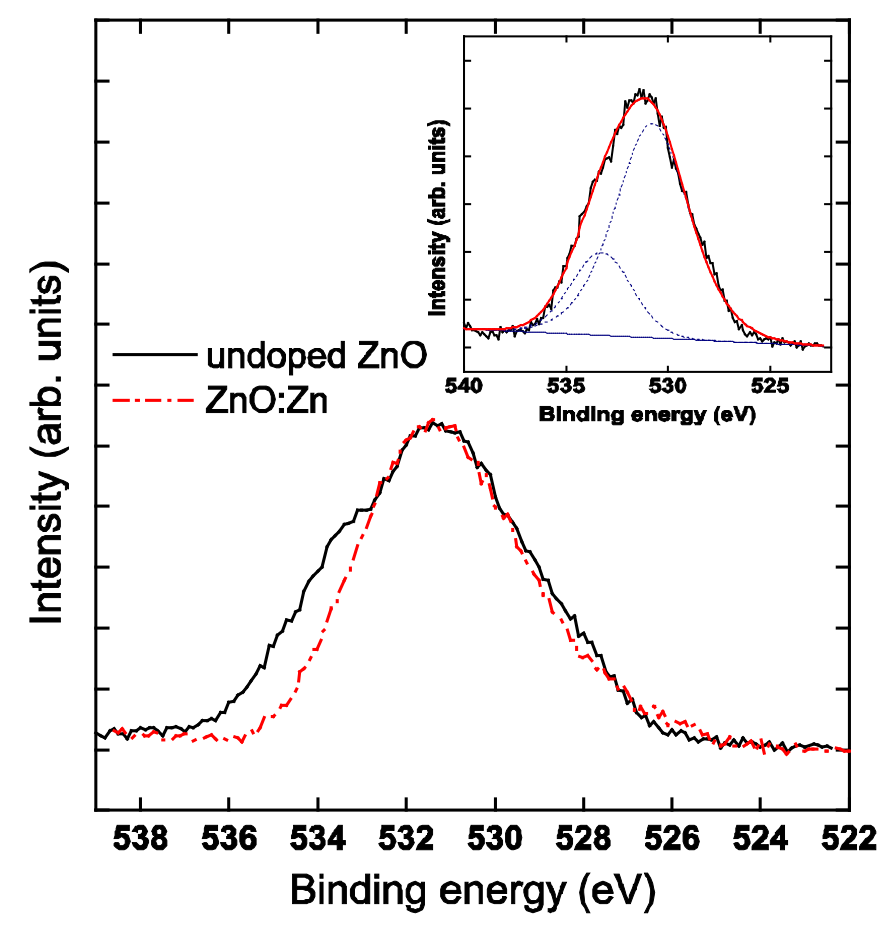


C. Ton-That et al.

Figure 3

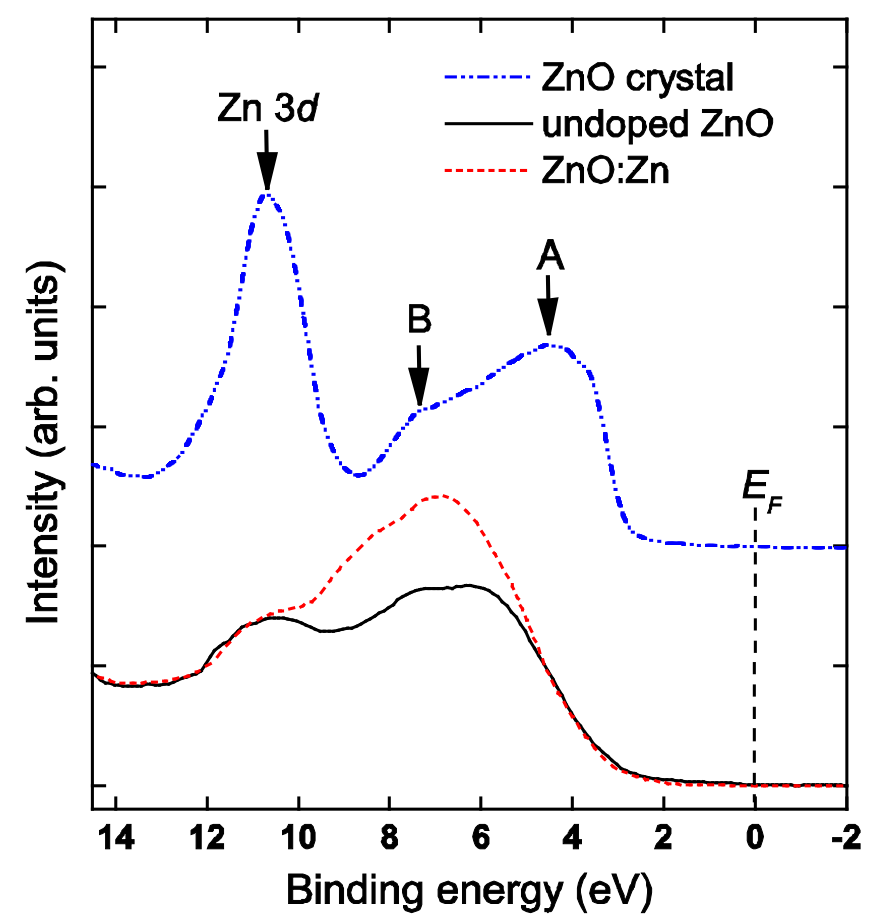


C. Ton-That et al.

Fig 4

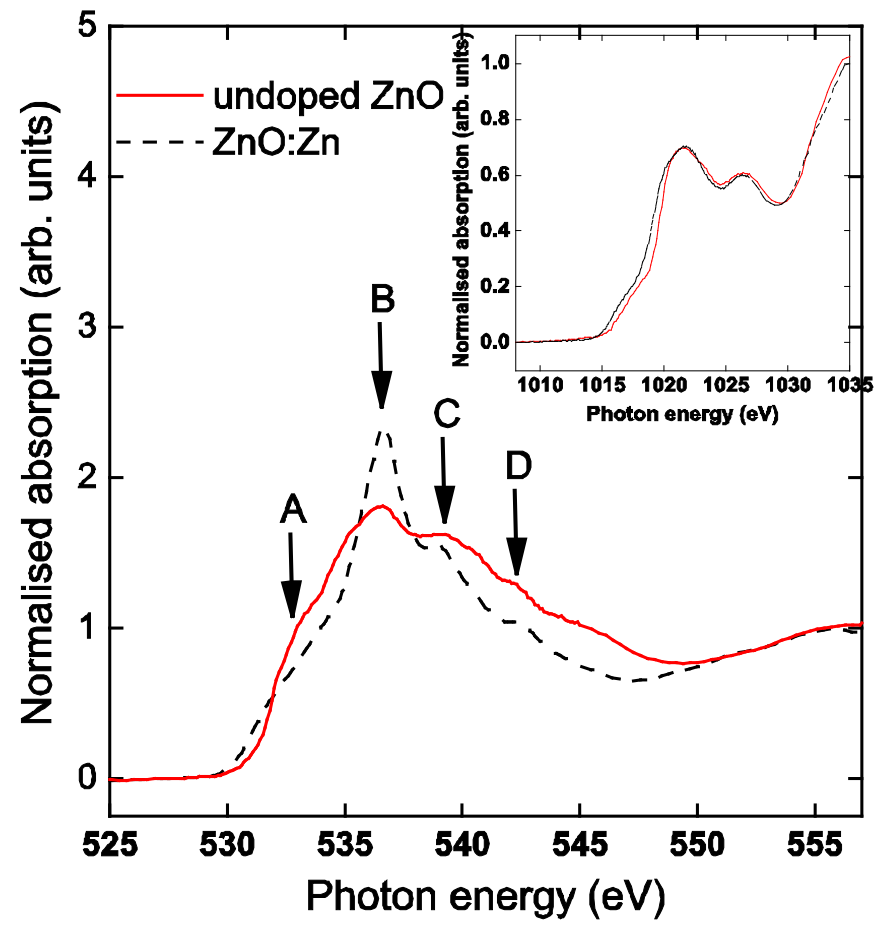

